Плющ О. Г., канд. техн. наук, доцент ${ }^{1}$ Рибидайло А. А., канд. техн. наук, ст. науч. співроб. ${ }^{2}$ (ORCID: 0000-0002-6156-469X)

1 - Державний університет телекомунікацій, Київ;

2 - Центр воєнно-стратегічних досліджень Національного університету оборони України імені Івана Черняховського, Київ

\title{
Алгоритм налаштування адаптивної антенної решітки, який не потребус присутності опорного сигналу
}

Резюме. Розроблено градієнтний алгоритм налаштування адаптивних антенних решіток, який не потребує формування опорного сигналу. Проведено імітаційне моделювання алгоритму та доведено його ефективність.

Ключові слова: адаптивні антенні решітки; градієнтні алгоритми налаштування; імітаційне моделювання; відношення корисний сигнал/завада.

Постановка проблеми. Адаптивні антенні решітки (ААР) знаходять широке застосування для розв'язання різноманітних задач у таких областях науки і техніки, як телекомунікації, радіо- та гідролокація. Існуе певна кількість достатньо простих, але не менш ефективних алгоритмів налаштування таких решіток. Але майже всі вони потребують присутності в тому чи іншому вигляді опорного сигналу, що обмежує їх область застосування. У деяких випадках опорний сигнал або неможливо створити взагалі, або це пов'язано 3 великими труднощами під час практичної реалізації. Наприклад, в імпульсній радіолокації короткої тривалості корисний сигнал має невідомий час надходження, що викликає великі проблеми під час використання його як референтного. 3 огляду на наведене, важливою $є$ задача пошуку та оцінювання ефективності простих алгоритмів налаштування АAР, які не потребують наявності опорного сигналу.

Аналіз останніх досліджень i публікацій. 3 початку розроблення та практичного застосування АAР питання покращення їх характеристик та розроблення нових алгоритмів для їх налаштування широко висвітлюються в науково-технічній літературі [4]. Зі зростанням обчислювальних можливостей процесорів сигналів, все більш складні алгоритми, зокрема пов'язані 3 обертанням кореляційної матриці, стають такими, що можуть бути реалізовані на практиці $[2,5]$. Тим не менш, прості градієнтні алгоритми не втрачають своєї привабливості для розробників АAР [2], особливо, коли розміри ААР суттєво зростають.

Зі стрімким поширенням мобільного зв'язку, ААР починають знаходити широке застосування в забезпеченні зв'язку між мобільними та базовими станціями [1], особливо в системах четвертого та п'ятого покоління.

На жаль, в літературі не проведено вичерпного аналізу щодо алгоритмів, які доцільно використовувати в ААР для систем мобільного зв'язку. Так, хоча в [1] і вказується що ААР дають суттєве покращення показників зв'язку в бездротових мережах, жодного адаптивного алгоритму не приведено i не надано будь-яких практичних рекомендацій щодо вибору цього алгоритму.

Мета статті $\epsilon$ розроблення алгоритму налаштування АAР, який не потребує наявності опорного сигналу i дослідження його ефективності та можливості застосування у сучасних ААР.

Виклад основного матеріалу. Для досягнення цієї мети розв'язуються такі наукові задачі:

аналіз існуючих алгоритмів та синтез алгоритму налаштування АAP який не потребує присутності опорного сигналу;

розроблення імітаційної моделі ААР на основі розробленого алгоритму налаштування;

імітаційне моделювання ААР та аналіз ефективності розробленого алгоритму.

Використання того чи іншого алгоритму налаштування АAР визначається розміром антенної решітки, необхідними показниками іiі ефективності та, особливо, наявним обчислювальним ресурсом $[2,3]$. Основними 3 існуючих алгоритмів можливо вважати градієнтні алгоритми, алгоритми безпосереднього обертання кореляційної матриці, рекурентні методи, та алгоритми випадкового пошуку $[2,3]$. Найпростішими в реалізації є градієнті алгоритми, оскільки вони потребують найменших обчислювальних 
витрат і до того ж забезпечують прийнятні показники якості.

Розглянемо градієнтний найскорішого спуску у разі опорного сигналу для алгоритм наявності методу середньоквадратичної помилки

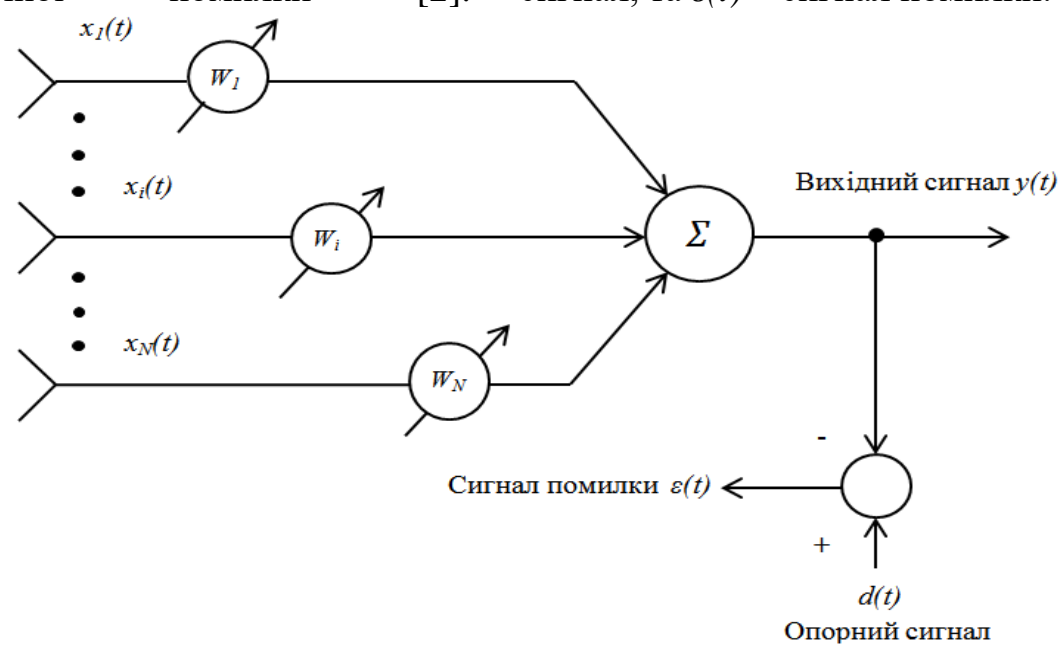

Структурна схема вузькосмугової решітки при відомому опорному або корисному сигналі наведена на рис. 1 , де $x_{i}(t)-$ сигнал прийнятий $i$-м елементом решітки, $w_{i}$-ваговий коеффіціент у $i$-му каналі, $d(t)-$ опорний [2]. сигнал, та $\varepsilon(t)$ - сигнал помилки.

Рис. 1. Структурна схема вузькосмугової антенної решітки при відомому корисному сигналі

Для антенної решітки на рис. 1 математичне сподівання квадрата помилки визначається формулою [2]

$$
E\left\{\varepsilon^{2}(t)\right\}=S-2 \mathbf{w}^{\mathbf{T}} \mathbf{r}_{\mathbf{x d}}+\mathbf{w}^{\mathbf{T}} \mathbf{R}_{\mathbf{x x}} \mathbf{w},
$$

де $\mathbf{r}_{\mathbf{x d}}$ - вектор кореляції прийнятих сигналів решітки $x_{i}(t)$ та опорного сигналу $d(t)$;

$\mathbf{R}_{\mathbf{x x}}$ - кореляційна матриця прийнятих сигналів;

$S$ - потужність корисного сигналу.

Відомо [2], що задача налаштування антенної решітки (рис. 1) полягає в мінімізації (1), завдяки вибору вагового вектора $\mathbf{w}$, до того ж мінімум (1) досягається, коли градієнт середньоквадратичної помилки дорівнює нулю:

$$
\nabla_{w}\left(\overline{\varepsilon^{2}}\right)=0
$$

Градієнт (1) визначається за формулою

$$
\nabla_{w}\left(\overline{\varepsilon^{2}}\right)=-2 \mathbf{r}_{\mathbf{x d}}+2 \mathbf{R}_{\mathbf{x x}} \mathbf{w}
$$

a оптимальний ваговий вектор співвідношенням

$$
\mathbf{w}_{\text {ОПТ }}=\mathbf{R}_{\mathbf{x x}}^{-1} \mathbf{r}_{\mathbf{x d}} \text {. }
$$

Вираз (4) $є$ добре відомим рівнянням Вінера-Хопфа у матричній формі.

Градієнтний алгоритм найскорішого спуску для налаштування антенної решітки (рис. 1) може бути представлений такою ітераційною формулою:

$$
\mathbf{w}(k+1)=\mathbf{w}(k)-\Delta_{s} \nabla_{w}\left[\overline{\left(\varepsilon^{2}(k)\right.}\right],
$$

де $\mathbf{w}(k+1)$ - нове значення вагового вектора у відлік часу $(k+1) T$; $\mathbf{w}(k)$ - значення вагового коефіцієнта у відлік часу $k T$;

$\Delta_{s}$ - константа, що визначає крок налаштування.

3 урахуванням (3), вираз (5) можливо переписати таким чином:

$\mathbf{w}(k+1)=\mathbf{w}(k)-2 \Delta_{s}\left(\mathbf{R}_{\mathbf{x x}} \mathbf{w}(k)-\mathbf{r}_{\mathbf{x d}}\right)$.

У (6) потрібно обчислювати значення градієнта у кожній точці у процесі налаштування, а для цього необхідно спочатку оцінити кореляційну матрицю i вектор кореляції прийнятих сигналів решітки $x_{i}(t)$ та опорного сигналу $d(t)$.

Для уникнення цього i відповідного спрощення процесу налаштування замість градієнта в (6) використовується його оцінка, а не саме значення [2]. У такому випадку зміни вагового вектора можливо представити у вигляді

$$
\mathbf{w}(k+1)=\mathbf{w}(k)-\Delta_{s} \tilde{\nabla}_{w}\left[\overline{\left(\varepsilon^{2}(k)\right.}\right],
$$

де $\tilde{\nabla}_{w}\left[\overline{\left(\varepsilon^{2}(k)\right.}\right]$ - являє собою оцінку градієнта.

За оцінку градієнта зазвичай використовується така [2]:

$$
\tilde{\nabla}_{w}=-2 \varepsilon(k) \mathbf{x}(k) .
$$

3 урахуванням (8), рекурентна формула (6) у комплексному вигляді виглядатиме:

$$
\mathbf{w}(k+1)=\mathbf{w}(k)+2 \Delta_{s} \varepsilon(k) \mathbf{x}^{*}(k),
$$

де * означає комплексне спряження.

Формула (9) має багато переваг та широко використовується для налаштування антенних решіток у різних галузях техніки. Але, 
як було показано вище, вона потребує наявності опорного сигналу. Нажаль, цю вимогу не завжди можливо задовольнити, особливо там, де корисні сигнали мають імпульсний характер, i це $є$ iï суттєвим недоліком.

Синтез градієнтного алгоритму, який не потребує наявності опорного сигналу.
На рис. 2 наведено схему вузькосмугової антенної решітки, яка налаштована на корисний сигнал $\mathrm{i}$ не потребує наявності опорного сигналу у явному вигляді. Налаштування на корисний сигнал відбувається у разі присутності фазообертачів у кожному каналі, i до того ж вважається, що напрямок приходу корисного сигналу відомий.

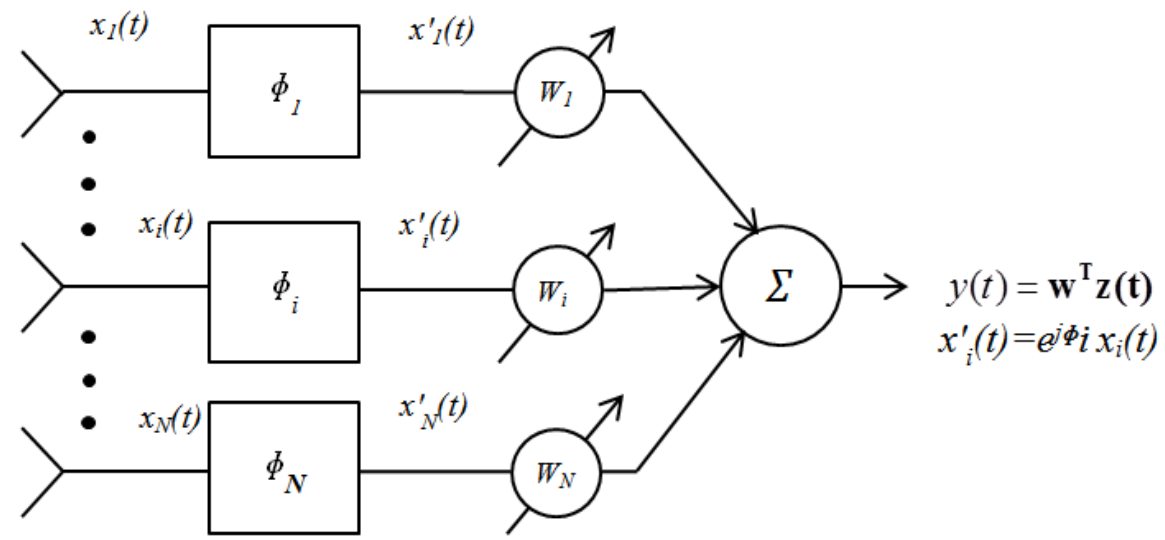

Рис. 2. Структурна схема вузькосмугової антенної решітки, яка налаштована на корисний сигнал

У разі, коли напрямок приходу корисного сигналу є відомим, можливо застосувати критерій мінімізації дисперсії (потужності) сигналу на виході решітки.

Вектор сигналів 3 елементів антенної решітки після фазообертачів буде мати вигляд

$$
\mathbf{x}^{\prime}(t)=\Phi \mathbf{x}(t),
$$

де $\Phi$ - діагональна матриця типу

$$
\Phi=\left(\begin{array}{ccc}
e^{i \Phi_{1}} & 0 & 0 \\
0 & \ddots & 0 \\
0 & 0 & e^{i \Phi_{N}}
\end{array}\right)
$$

Дисперсія або потужність шуму на виході антенної решітки під час перетворення (10) не змінюється і дорівнює:

$$
\operatorname{var}[y(t)]=\mathbf{w}^{\mathbf{T}} \mathbf{R}_{\mathbf{x}^{\prime} \mathbf{x}^{\prime}} \mathbf{w}=\mathbf{w}^{\mathbf{T}} \mathbf{R}_{\mathbf{x x}} \mathbf{w} .
$$

Критерій мінімуму дисперсії шуму полягає у мінімізації (11) за умови обмеження

$$
\mathbf{w}^{\mathbf{T}} \mathbf{1}=1,
$$

де $\mathbf{1}=[1,1, \ldots, 1]^{\mathbf{T}}$.

Для розв’язання цієї задачі мінімізації створюється модифікований критерій ефективності

$$
\mathfrak{R}_{\text {мди }}=\frac{1}{2} \mathbf{w}^{\mathbf{T}} \mathbf{R}_{\mathbf{x x}} \mathbf{W}+\lambda\left[1-\mathbf{w}^{\mathbf{T}} \mathbf{1}\right],
$$

де $\lambda$ - множник Лагранжа.
Для винайдення оптимального вектора коефіцієнтів в (12) потрібно знайти градієнт. Він дорівнює:

$$
\nabla_{w} \mathfrak{R}_{\text {мәц }}=\mathbf{R}_{\mathbf{x x}} \mathbf{w}-\lambda \mathbf{1} .
$$

3 урахуванням обмеження, що накладається на коефіцієнти решітки, оптимальний вектор в (13), коли градієнт дорівнює нулю, виглядатиме [2]:

$$
w_{\text {мди }}=\mathbf{R}_{\mathbf{x x}}^{-1} \mathbf{1} \lambda,
$$

де $\lambda=\frac{1}{\mathbf{1}^{\mathbf{T}} \mathbf{R}_{\mathbf{x x}}^{\mathbf{- 1}} \mathbf{1}}$.

До того ж слід додати що $\lambda$ відповідає значенню дисперсії шуму на виході решітки (рис. 2) під час налаштування на оптимальний вектор коефіцієнтів (14) [2].

Наведені формули дають змогу отримати градієнтний алгоритм адаптації решітки без необхідності формування опорного сигналу.

Градієнтний алгоритм (5) може бути записаний для антенної решітки зображеної на рис. 2 з урахуванням (13) i (15) у такому вигляді:

$$
\mathbf{w}(k+1)=\mathbf{w}(k)-\Delta_{s}\left(\mathbf{R}_{\mathbf{x x}} \mathbf{w}-\frac{\mathbf{1}}{\mathbf{1}^{\mathbf{T}} \mathbf{R}_{\mathbf{x x}}^{-1} \mathbf{1}}\right)
$$

Звичайно для використання процедури (16) потрібно проводити визначення градієнту на кожному кроці ітерацій. Проте, як i в попередньому випадку, можливо перейти до оцінки градієнту. Оцінка градієнту може бути отримана за умови використання для цієї 
оцінки тільки одного відліку сигналів. Отже, замість $\quad \mathbf{R}_{\mathrm{xx}} \mathbf{w}-\frac{\mathbf{1}}{\mathbf{1}^{\mathrm{T}} \mathbf{R}_{\mathrm{xx}}^{-1} \mathbf{1}} \quad$ можливо використовувати

$$
\mathbf{x}^{\prime}(k) \mathbf{x}^{\top \mathbf{T}}(k) \mathbf{w}(k)-y(k) y(k)^{*} \mathbf{1}
$$

$\mathrm{y} \quad(17) \quad$ кореляційна матриця представлена у вигляді продукту двох

$$
\mathbf{w}(k+1)=\mathbf{w}(k)-\Delta_{s}\left(\mathbf{x}^{\prime}(k) \mathbf{x}^{\mathbf{T}}(k) \mathbf{w}(k)-y(k) y(k)^{*} \mathbf{1}\right)
$$

Для оцінювання якості роботи розробленого алгоритму проведемо його імітаційне моделювання із застосуванням середовища Matlab.

Імітачійне моделювання алгоритму (18)

Імітаційне моделювання було проведено для лінійної вузькосмугової антенної решітки 3 такими параметрами: кількість елементів в антенній решітці - 9, відстань між елементами - половина тривалості хвилі, потужність внутрішнього шуму в кожному каналі решітки - одиниця.

Для оцінювання перехідного процесу налаштування використовувалося відношення корисний сигнал/завада на виході решітки. Для моделювання шумових процесів застосовувалися некорельовані відліки векторів сигналів після фазообертачів, а потужність сигналу на виході у вигляді потужності одного відліку вихідного сигналу.

3 огляду на наведене, в кінцевому вигляді алгоритм, який пропонується для використання в адаптивній антенній решітці, що зображена на рис. 2, матиме вигляд:

розподілені за нормальним законом. Потужність завадових сигналів вимірювалася в умовних одиницях відносно потужності внутрішнього шуму.

Результати моделювання процесу адаптації антенної решітки за допомогою розробленого алгоритму (18) наведені на рис. 3. У завадовій ситуації на рис. 3 було імітовано три сторонніх джерела шумових сигналів 3 кутами падіння відносно нормалі до розкриву решітки $-28.648,-57.296$ та 0 градусів, 3 відповідними рівнями потужності щодо внутрішніх шумів у каналах 200, 300 та 250 одиниць. Кут падіння корисного сигналу дорівнював 60 градусів при потужності 100 одиниць.

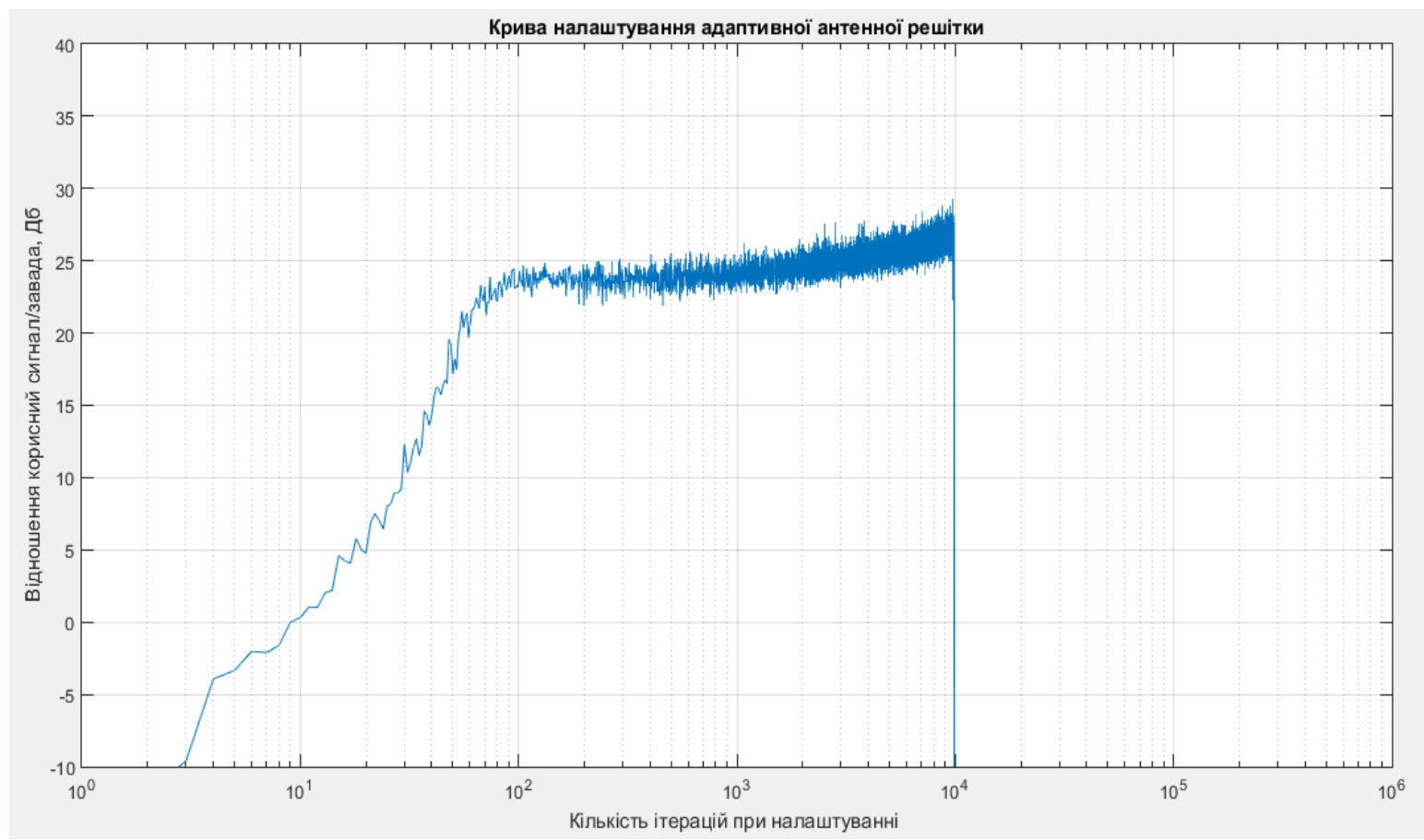

Рис. 3. Крива налаштування адаптивної антенної решітки без нормування вагового вектора

Для отримання кривої проводилося налаштування по 1000000 відліків вхідних сигналів решітки, до того ж усереднення відношення корисний сигнал/завада відбувалося за 50 незалежними реалізаціями.

Потенційно можливе відношення корисний сигнал/завада, обчислене по ідеальній кореляційній матриці за відомими формулами [2] для завадової ситуації, на рис. 3. складає приблизно 29,3 дБ.

Аналіз результатів моделювання за алгоритмом (18) показує, що у разі наближення кривої відношення корисний сигнал/завада до потенційного значення 29,3 дБ процес налаштування стає нестабільним і відбувається 
збудження при досягненні приблизно 10000 ітерацій, як наочно демонструє рис. 3 .

Аналіз показує, що вказане неочікуване переривання процесу адаптації відбувається за рахунок того, що при зменшенні вихідних завадових сигналів при налаштуванні, оцінка градієнту (17), що була використана під час отримання (18) стає неточною внаслідок присутності внутрішніх шумів решітки.

$$
\begin{aligned}
\mathbf{w}(k+1) & =\mathbf{w}(k)-\Delta_{s}\left(\mathbf{x}^{\prime}(k) \mathbf{x}^{\mathbf{T}}(k) \mathbf{w}(k)-y(k) y(k)^{*} \mathbf{1}\right) \\
w_{i}(k+1) & =\frac{w_{i}(k+1)}{\sum_{n=1}^{N} w_{n}(k+1)}
\end{aligned}
$$

де $N$ - кількість елементів в антенній решітці.

Імітаиійне моделювання алгоритму (19)

На рис. 4 наведені результати налаштування адаптивної антенної решітки згідно з алгоритмом (19) для тієї ж завадової ситуації, що i в попередньому випадку. Результати моделювання демонструють, що нормування вагового вектора згідно 3 (19) на кожному кроці налаштування усуває вказані раніше недоліки.

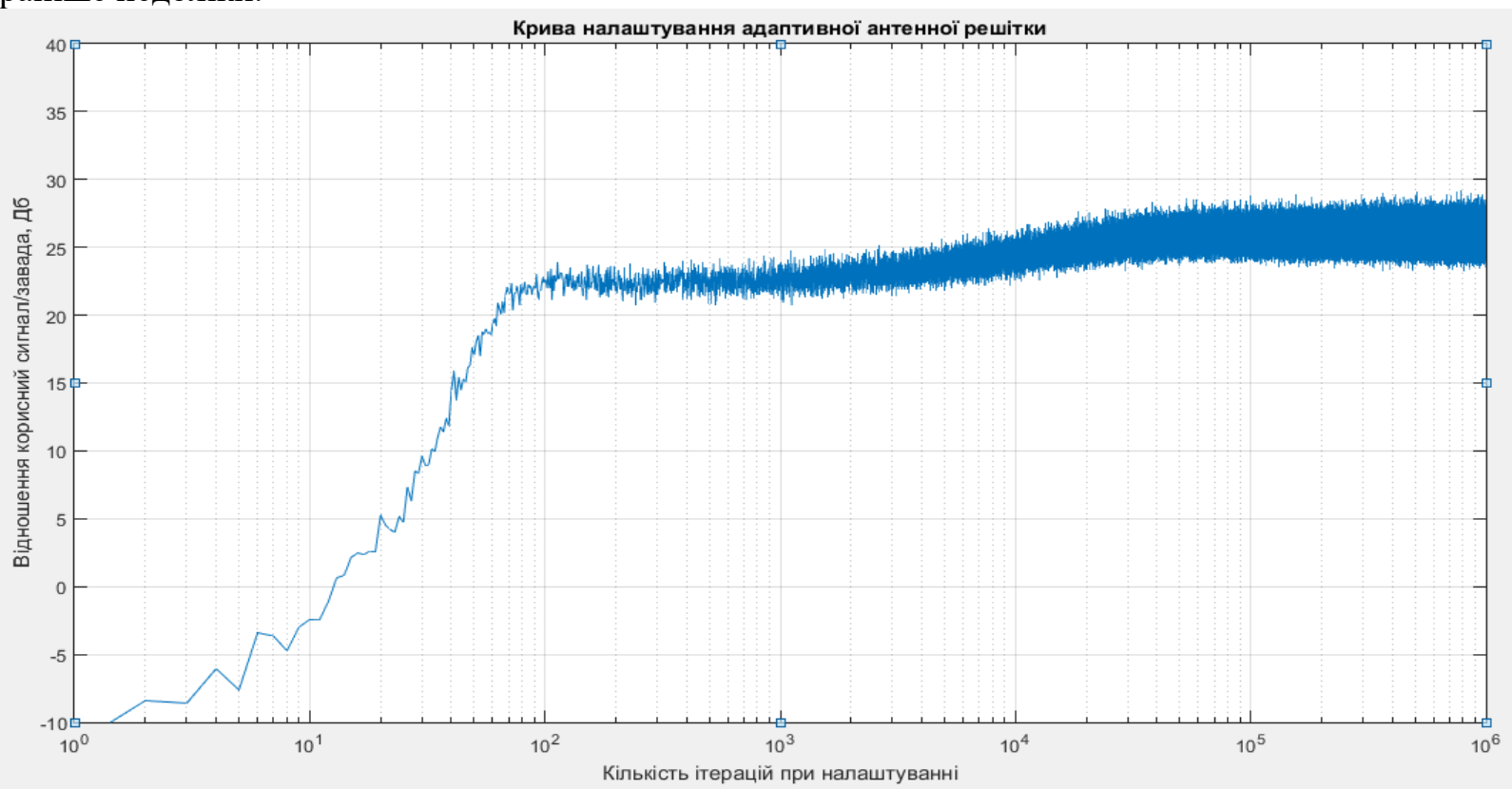

Рис. 4. Крива налаштування адаптивної антенної решітки з нормуванням вагового вектора Ідеальна або оптимальна діаграма решітки, для завадової ситуації описаної вище, наведена на рис. 5. На ній чітко проглядається максимум діаграми на напрямок приходу корисного сигналу, що відповідає 60 градусам або 1,047 радіан, та мінімуми у напрямках приходу трьох завадових сигналів: $-57,296$ або мінус один радіан, -28,648 або мінус 0,5 радіан, та 0 градусів або радіан.

Діаграма направленості побудована за допомогою вагового вектора отриманого за
Для виправлення вказаного недоліку в роботі пропонується доповнити алгоритм налаштування (18) процедурою нормування вагового вектора решітки на кожному кроці налаштування таким чином, щоб його модуль дорівнював одиниці. 3 урахуванням цього алгоритм налаштування антенної решітки наприкінці виглядатиме: розробленого алгоритму (19) додатково було побудовано діаграми направленості антенної решітки по ваговому вектору отриманому за результатами налаштування за процедурою (19) та по оптимальному ваговому вектору, що отриманий 3 ідеальної кореляційної матриці решітки. 


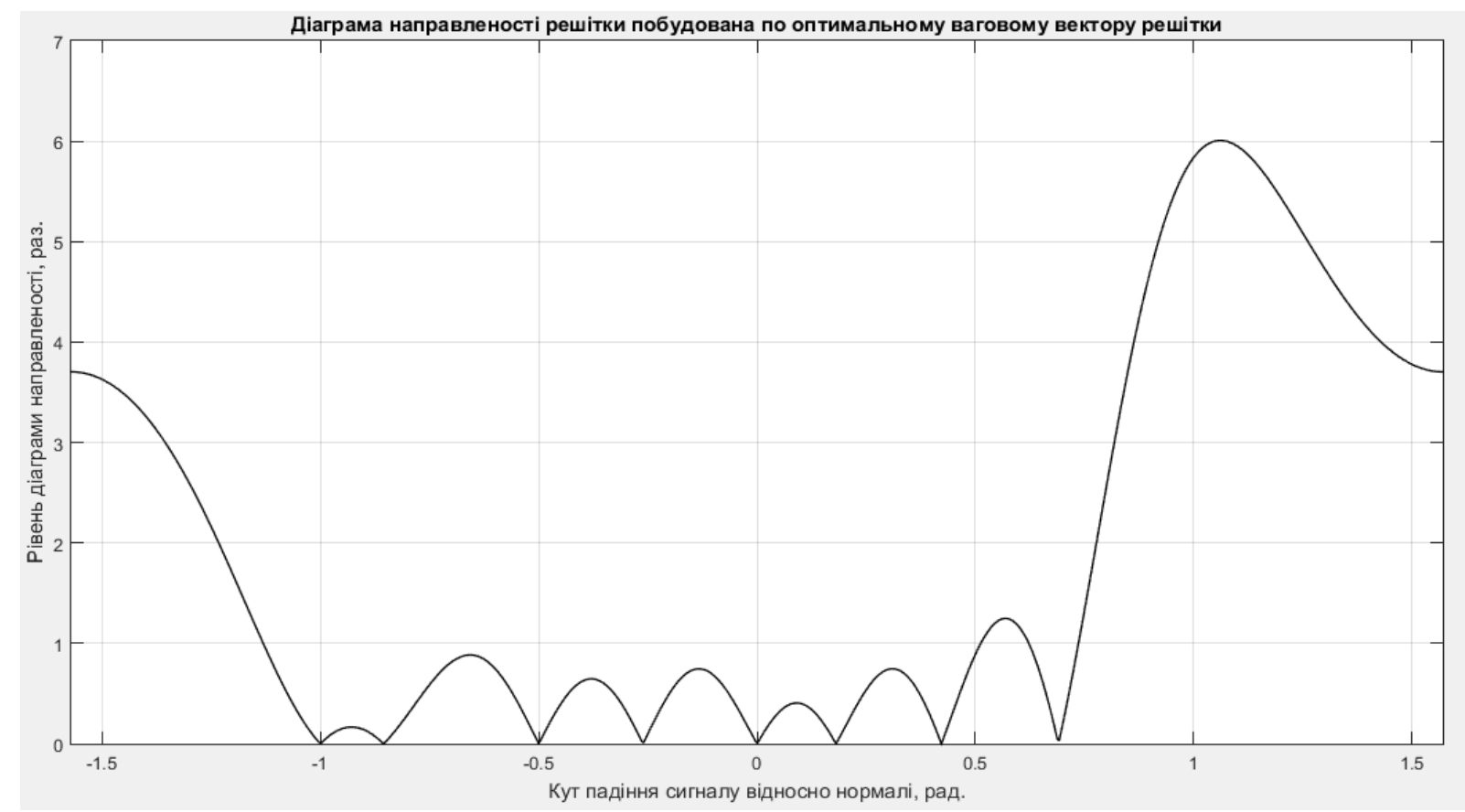

Рис. 5. Діаграма направленості антенної решітки побудована по оптимальному ваговому вектору решітки

Висновки. Адаптивні антенні решітки знаходять все більше застосування в системах радіолокації та телекомунікаціях, особливо мобільному зв'язку четвертого та п'ятого поколінь. Існують прості та ефективні градієнтні алгоритми найскорішого спуску, які дають змогу здійснювати налаштування антенних решіток. Головним недоліком цих алгоритмів $\epsilon$ необхідність мати опорний (корисний) сигнал для здійснення процедури адаптації. На жаль, можливість згенерувати потрібний опорний сигнал не завжди існує в реальних системах, особливо в імпульсній радіолокації.

У роботі розроблено градієнтний алгоритм (19) для налаштування адаптивної антенної решітки, який не потребує наявності опорного сигналу. Налаштування антенної решітки на корисний сигнал відбувається за відомим кутом надходження цього сигналу, а придушення небажаних завадових сигналів за допомогою алгоритму мінімізації дисперсії шуму.

Моделювання розробленого алгоритму підтвердило його працездатність та ефективність, і коректність всіх припущень зроблених авторами при його синтезі.

Авторам роботи не відомо про існування алгоритму (19) та про його опис у вітчизняній та зарубіжній літературі, вони вважають його оригінальним i таким що вперше пропонується до застосування.

Точність та швидкість налаштування у поєднанні 3 простотою розробленого алгоритму налаштування адаптивної решітки
(19) свідчать про можливість його застосування в сучасних системах радіолокації та мобільного зв'язку.

Подальші дослідження доцільно зосередити на розширенні можливостей застосування алгоритму (19) у двомірних (плоских) антенних решітках та перевірці його ефективності у різних завадових ситуаціях. Крім того, окремих досліджень потребують питання вибору константи в (19) що визначає крок налаштування.

\section{СПИСОК ВИКОРИСТАНОЇ ЛІТЕРАТУРИ}

1. Гепко И. А., $\quad$ Олейник В. Ф., $\quad$ Чайка Ю. Д., Бондаренко А. В. Современные беспроводные сети: состояние и перспективы развития. - Киев: "ЕКМО", 2009. - 672 c.

2. Монзинго Р. А., Миллер Т. У. Адаптивные антенные решетки: Введение в теорию: Пер. с англ. - Москва: Радио и связь, 1986. - 448 с.

3. Радиоэлектронные системы: Основы построения и теория. Справочник. Изд. 2-е, перераб. и доп. / Под ред. Ширмана Я. Д. - Москва: Радиотехника, 2007. - 512 с.

4. Справочник по радиолокации. Под ред. М. Сколника. Нью Йорк, 1970. Пер. с англ. (в четырех томах) под общей ред. К. Н. Трофимова. Том. 2. Радиолокационные антенные устройства. Под ред. П. И. Дудника. - Москва: “Сов. Радио”, 1977. -408 c.

5. Уидроу Б., Стирнз С. Адаптивная обработка сигналов: Пер. с англ. - Москва: Радио и связь, 1989. - $440 \mathrm{c}$.

6. Ширман Я. Д., Манжос В.Н. Теория и техника обработки радиолокационной информации на фоне помех - Москва: Радио и связь, 1981. $416 \mathrm{c}$. 
Плющ А. Г., канд. техн. наук, доцент ${ }^{1}$;

Рыбыдайло А. А., канд. техн. наук, ст. науч. сотрудник ${ }^{2}$

1 - Государственный университет телекоммуникаций, Киев;

2 - Центр военно-стратегических исследований Национального университета обороны Украины имени Ивана Черняховского, Киев;

\section{Алгоритм настройки адаптивной антенной решетки который не требует присутствия опорного сигнала}

Резюме. Разработан градиентный алгоритм настройки адаптивных антенных решеток который не требует формирования опорного сигнала. Проведено имитационное моделирование алгоритма и доказана его эффективность.

Ключевые слова: адаптивные антенные решетки; градиентные алгоритмы настройки; имитационное моделирование; отношение полезный сигнал/помеха.

A. Pliushch, PhD (Technical), assistant professor $^{1}$;

A. Rybydajlo, PhD (Technical), senior researcher ${ }^{2}$;

1 - State University of Telecommunications, Kyiv;

${ }^{2}$ - Center for Military and Strategic Studies of the National Defence University of Ukraine named after Ivan Cherniakhovskyi, Kyiv

Adaptive antenna array adaptation algorithm that does not require reference signal presence

Resume. A gradient algorithm of adaptive antenna arrays adjustment that does not require reference signal presence is developed. Computer simulation of the algorithm is carried out and its efficiency is proven.

Keywords: adaptive antenna arrays; gradient algorithms of adaptation; computer simulation; signal-tointerference ratio. 